\title{
Antimicrobial and Antiproliferative Activities of Depside Compound Isolated from the Mycobiont Culture of Parmotrema austrosinense (Zahlbr.) Hale
}

\author{
Kalidoss Rajendran ${ }^{1}$ (D), Shanmugam Poornima² ${ }^{2}$ and \\ Ponmurugan Ponnusamy (iD) ${ }^{1 *}$ \\ ${ }^{1}$ Biomedical Research Laboratory, Department of Botany, Bharathiar University, Coimbatore - 641 046, \\ Tamil Nadu, India. \\ ${ }^{2}$ Department of Biotechnology, K.S.R. College of Technology, Tiruchengode - 637 215, \\ Tamil Nadu, India.
}

\begin{abstract}
Substances which are normally secondary metabolites in a lichen are known to possess various medicinal properties but little is known about the biological activities of compounds present in these mycobiont culture extract. The objectives of the present study were isolation and optimization of growth conditions of the mycelia from Parmotrema austrosinense and assess the antiproliferative and antimicrobial activities of acetone extracts. The extraction of bioactive compound from mycobiont culture was achieved by using acetone and standard Soxhlet extraction procedures. The culture extract was subjected to silica gel column chromatography and detection of compound in thin layer chromatography. HPLC, UV vis, IR spectra, microcrystallization and NMR were done for the purified compound. The antimicrobial activity in the extracts were assayed using the standard disc diffusion and broth microdilution protocol against microbial strains. The lecanoric acid in the extracts was purified and MTT method was applied to assess antiproliferative activity against DLA cancer cells. The culture extract containing lecanoric acid exhibited antimicrobial activity against the test strains with the Minimum Inhibitory Concentrations varied between $0.83 \pm 0.28$ and $2.3 \pm 1.5 \mathrm{mg} \mathrm{mL}^{-1}$. The lecanoric acid inhibited the growth of DLA cancer cells with inhibitory concentration (IC50) of about $42 \pm 1.5 \mu \mathrm{g}$ $\mathrm{mL}^{-1}$. Conclusion: The result of the present study suggests that this compound might possess potent antitumor property and should be further analysed using appropriate animal model and clinical trials.

Keywords: Lichen, Mycobiont, Lecanoric acid, Microcrystallization, Antiproliferative
\end{abstract}

*Correspondence: drponmurugan@gmail.com

(Received: August 31, 2020; accepted: September 21, 2020)

Citation: Rajendran K, Poornima S, Ponnusamy P. Antimicrobial and Antiproliferative Activities of Depside Compound Isolated from the Mycobiont Culture of Parmotrema austrosinense (Zahlbr.) Hale. J Pure Appl Microbiol. 2020;14(4):2525-2541. doi: 10.22207/JPAM.14.4.29

(C) The Author(s) 2020. Open Access. This article is distributed under the terms of the Creative Commons Attribution 4.0 International License which permits unrestricted use, sharing, distribution, and reproduction in any medium, provided you give appropriate credit to the original author(s) and the source, provide a link to the Creative Commons license, and indicate if changes were made. 


\section{INTRODUCTION}

Lymphoma cancer is one of the lethal syndromes in which the highest deaths per year around the globe is recorded. More than 79,990 peoples affected worldwide due to this disease from which 26,167 have died ${ }^{1}$ with a focus on geographic variability across 20 world regions. There will be an estimated 18.1 million new cancer cases (17.0 million excluding nonmelanoma skin cancer. The common signs of lymphoma cancer include the swelling of the lymph nodes, the thymus, tonsils, spleen and other illnesses in the lymphatic system. Microbial disease is the most common form of disease next to cancer. Although drug resistant microbial strains are the most dangerous pathogen that leads to death especially in rural India, microbial disease incidence and mortality rate has also increased in recent years. For instance, the drug resistant microbial strains take away the lives of about 23,000 people every year $^{2}$. The mortality rate is so high which may be attributed to lack of effective antimicrobial and anticancerous agent in effective treatment protocol. According to Fazoli et $a^{3}$. who have warned that the microbes developing the drug resistance are being acquired through many ways, so controlling or treatment with conventional antibiotics alone might not be sufficient. So, present study is to isolate and characterize the bioactive compound from lichen mycobiont culture extract and provide more effective treatment. Scores of lichen extract and their therapeutic uses are well known but little is known about the extraction of bioactive compound and biological activities present in these culture extract. Medicinal lichens are rich sources of secondary metabolites such as antitumor substances, antiviral compounds, organic acids, anti-inflammatory, cytotoxic effects and antimicrobial substances that can be effective against the range of diseases ${ }^{4-6}$. With the development of drug resistant strains and new diseases, the need for novel medicines has also increased. With people focussing on the traditional system of medicine, there is a surge for the isolation of new compounds. Indigenous tribal communities have also witnessed the economic importance of lichen as a source of antibacterial or antiviral agents. It is well known that mycobiont (fungal partner) exhibits symbiotic relationship with photobiont (algal partner) which acts as the source of secondary metabolites used to synthesize biochemical compounds important in pharmaceuticals. Among 1050 known secondary metabolites in lichens, usnic acid, a dibenzofuran compound is extensively used and one of the few that is commercially available under the name Usno. This medication is available in Russia, Germany and Europe. The lecanoric acid is prevalent in lichens and its main source is the species of Stereocaulon curatum, P. austrosinense, P. tinctorum, P. stuppeum and Umbilicaria antarctica ${ }^{7}$. Most important investigation on lichens bioactive compounds included in vitro antiproliferative activity and extraction of bioactive molecules from cultured lichens and mycobiont for inhibition of bacteria and fungi. In Japan, a large number of studies are being carried out in different lichen species for bioprospecting studies ${ }^{8}$.

Despite the fact that mycobiont culture extract portrays some medicinal compounds as that of their host medicinal lichens, very little has been done in their in vitro procedure and establishment of the presence of antimicrobial activities against test strains. The lichens are slow growers. Some require 100 years to reach $1 \mathrm{~mm}$ length as in Rhizocarpon geographicum and others (Usnea spp.,) may require one year to attain a few centimeters. Moreover, many lichens are now harvested in bulk in search of medicines which even threaten their abundance and diversity ${ }^{9}$. Due to availability of scanty amount of substances in thallus but wide in its application, it has triggered a serious attention to lichenologists community to explore the knowledge of isolation and purification of lichen compound from mycobiont culture and study their associated medicinal applications including antimicrobial and anti-cancerous activities. The population of lichens has declined due to climate change, industrial and automobile smokes and anthropogenic activities in forests.

Therefore, current study was intended to inventory the isolation of mycobiont from selected $P$. austrosinense lichen thallus and determined to study their antimicrobial and anticancer activities against microbial test strains of medical importance and DLA cells; respectively. However initial contributions to the identification of lichen substances in the axenic lichen forming fungal culture was made during 1990. In Korea, Hur et al. ${ }^{10}$ first isolated mycobiont culture from Heterodermia 
spp. by spore discharge method and concentrated culture filtrate extract which showed antifungal effect against few phytopathogens. The specific objectives of current investigation were to isolate and identify mycobionts from $P$. austrosinense thallus and to screen for antimicrobial and anticancer activities.

\section{MATERIALS AND METHODS Chemicals \& Reagents}

Potato dextrose agar (PDA), Modified Bold's Basal Salt medium (MBBS), Malt Yeast Extract agar (MYE), spot test reagents (KOH), calcium hypochlorite ( $C$ test reagent), phenylene diamine (PD test reagent), Silica gel (230-400 mesh), Standard solution as Chloramphenicol $(25 \mathrm{mg} / \mathrm{mL}$ distilled water) and Fluconazole $(25 \mathrm{mg} /$

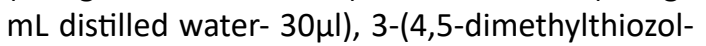
2-yl)-3,5-diphenyl tetrazolium bromide (MTT), Iscove's Modified Dulbecco's Medium (IMDM), trypsin-EDTA, Fetal Bovine Serum (FBS) and Phosphate Buffer Saline (PBS) were purchased from Himedia laboratories, Mumbai, India. Hexane, benzene, ethyl acetate, sulphuric acid, methanol and other solvents were purchased from SRL Ltd, Mumbai. All the chemicals purchased were of analytical grade with high purity.

\section{Collection and identification of $P$. austrosinense}

The lichen samples $P$. austrosinense (Zahlbr.) Hale were collected from Kodaikanal hills, Tamil Nadu, India, a part of Western Ghats, at an elevation of $2130 \mathrm{~m}$ above mean sea level, a latitude of $10^{\circ} 14^{\prime} 17.2^{\prime \prime} \mathrm{N}$ and longitude of $77^{\circ} 29^{\prime} 21.06^{\prime \prime} \mathrm{E}$ and brought to the laboratory for the present study ${ }^{11}$. The Awasthi's lichen identification manual ${ }^{12}$ was followed for matching the identification characters of the lichen samples. The samples were deposited at National Botanical Research Institute (NBRI), Lucknow, Uttar Pradesh, India (Accession No. 35618) as repository specimen.

Isolation and culture conditions of mycobiont from $P$. austrosinense

The isolation of mycobionts from $P$. austrosinense was carried out from individual part of the thallus using methods described by Yoshimura et al. ${ }^{8}$. The separated thallus was carefully washed in tap water to remove all adhering soil contaminants and then air-dried. Samples were excised into fragments of about
$5 \mathrm{~cm}$ and dipped in $0.1 \%$ tween 20 for a few seconds. Then the samples were surface sterilized by soaking sequentially in $70 \% \mathrm{C}_{2} \mathrm{H}_{5} \mathrm{OH}$ for three minutes, followed by $0.1 \%$ mercuric chloride for $1 \mathrm{~min}, 70 \% \mathrm{C}_{2} \mathrm{H}_{5} \mathrm{OH}$ for two minutes, then washed 3 times with sterile distilled water for one minute each. Samples were dried into lamina airflow chamber. The inner filaments of about $0.5 \mathrm{~cm}$ in length were dissected and placed in MYE (Malt-Yeast Extract) and PDA (Potato dextrose agar) agar media containing petri plates ${ }^{11}$ were prepared in sterile $90 \times 14 \mathrm{~mm}$ plates. Thereafter dissected fungal filament was placed on Petri plates containing MYE and PDA. The plates were kept in an incubator at $27 \pm 2^{\circ} \mathrm{C}$ for $4-8$ weeks in the dark. They were observed frequently to check the growth of fungal colonies. The purification of fungi was carried out using hyphal tip method, where by the hyphal tip of growing endophytic fungus was cut using a sterile blade and transferred to a PDA plate followed by room temperature incubation for 7-14 days. The pure culture was then obtained by serial sub culturing in slants. The fungal filament was observed by adding a drop of cotton blue-lactophenol stain under the high power microscope (Leitz Loborlux-S Photomicroscope) fitted with an ocular meter and determined the cell size. Once the pure culture of mycobiont was isolated from the lichen it was then mass cultured by shake culture. Culture conditions and media were altered so as to obtain the desired secondary metabolites.

\section{Production of lecanoric acid}

The mycobiont of $P$. austrosinense lichen thallus can produce lecanoric acid by fermenting sugars. The main factor which determines their compound production is their choice of production media. MBBS medium13 was prepared containing $1 \%$ potassium nitrate and $4 \%$ sucrose in each flask and inoculated with mycobiont isolate of $P$. austrosinense. The flasks with inoculum were incubated for $4-8$ weeks at $25^{\circ} \mathrm{C}$. The culture flask was placed shaking on a shake incubator and agitated at $150 \mathrm{rpm}$. Following incubation, a limited number of flasks were taken at regular intervals of time (one week) and the culture extract was extracted with acetone. The preparation of the culture extract was done with the Soxhlet apparatus. The mycobiont culture was packed in to a thimble made out of filter paper and sealed. This 
was then placed in the extractor and filled with 500 $\mathrm{mL}$ acetone and boiled upto $70^{\circ} \mathrm{C}$ for 15 refluxes. The crude culture extract was concentrated using rotary vacuum evaporator and concentrated powder was stored at $-20^{\circ} \mathrm{C}$ until further use. The culture extract was proceeded to examine for the detection of lichen compounds using TLC and microcrystallization tests.

Proof of lecanoric acid by microcrystallization test

Mycobiont culture extract was observed under the microscope for detecting the shape of microcrystals. For this, few drops of culture extract were placed on a glass slide in which 2-3 drops of GAW (Glycerol: Alcohol: Water, 1:1:1) solution were added. A cover slip was applied and the slide and gently heated for a few seconds. The slide was observed under the microscope (10 X objective lens) for the evidence of microcrystals formation ${ }^{14}$. Identification of lecanoric acid by UV-Visible Spectroscopic analysis

UV-Vis spectra was done using the standard procedures ${ }^{15}$. Five $\mathrm{mL}$ of mycobiont culture extract was analyzed under visible UVVisible spectrophotometry. The extract was scanned at intervals of $2 \mathrm{~nm}$ in the wavelength ranging from 200 to $1100 \mathrm{~nm}$ using the PerkinElmer Spectrophotometer (Hitachi U-2900, Japan) and the characteristic peak values were recorded.

Separation of lecanoric acid by Thin Layer Chromatography (TLC) method

The lecanoric acid was identified using TLC method ${ }^{14,16}$. complanata, R. dendriscoides, R. gracilis, R. peruviana and R. sprengelii. This study aimed to optimize the culture conditions and nutrient requirements of the selected mycobionts. The aposymbiotic R. complanta was successfully isolated from ascospores, while aposymbiotic R. peruviana was obtained from thallus fragments. In R. peruviana the production of secondary metabolites was investigated under aposymbiotical growth conditions using HPLC. When cultivated on solid medium, this mycobiont produced the typical chemosyndrome (sekikaic acid and satellite compounds. Lichen compound was extracted from mycobiont culture using $10 \%$ acetone by filtration method. On the immediate border ( $2 \mathrm{~cm}$ above) of the Silica gel $\mathrm{G}$ coated TLC plate a mark in line was drawn by a pencil. Three pencil marks (A, B and C) were indicated on the pencil line with the equal distances of 0.8 $\mathrm{cm}$ each. With the help of a capillary tube, heavy suspension of control (usnic acid) was loaded on the pencil mark indicated $A$ and $B$. The compound obtained from culture extract was directly applied to TLC plate marked C. The plate was air dried and developed to $13 \mathrm{~cm}$ height in a rectangular thin layer chromatography chamber previously saturated with TDA solvent mixture (Toluene: 1 , 4 Dioxane: Acetic acid, 180: 45: 05). A 10 per cent aqueous sulfuric acid solution was sprayed over the TLC plate, and mounted in a preheated oven at $110^{\circ} \mathrm{C}$ temperature the coloured spots were witnessed clearly.

Isolation and purification of lecanoric acid by column chromatography

The mycobiont extract was found to contain the bioactive lichen compound lecanoric acid with anticancer and antimicrobial activity was subjected to silica gel chromatography and simultaneous detection of a single component in TLC. Silica gel slurry soaked in hexane was packed in a chromatographic column $(60 \mathrm{~cm}$ $\times 18 \mathrm{~mm}$ ). Lichen mycobiont culture extract was resuspended with $5 \mathrm{~mL}$ acetone, and mixed with silica gel in a Petri dish and loaded in the column. The substances were eluted regularly by increasing the polarity of the eluent. The solvent used in the chromatographic technique was absolute benzene and $5 \%$ ethyl acetate in benzene. The solvent from the elute was evaporated in vacuo and the substances in the residue was recrystallized using $50 \%$ acetone in water to purify lecanoric acid.

Identification of lecanoric acid by HPLC

Chemical investigation of the polyphenolic compound lecanoric acid known to exhibit different biological activities was done through HPLC technique. The compounds extracted from lichen mycobiont was directly applied to HPLC on a (Rt 25 min) $4.6 \times 150$ mm $5 \mu \mathrm{M} \mathrm{C18} \mathrm{column}$ (Shimadzu, Japan). The mobile phase was $\mathrm{MeOH}$ : $\mathrm{H}_{2} \mathrm{O}: \mathrm{H}_{3} \mathrm{PO}_{4}$ (80:20:1) and it's the flow rate was $1 \mathrm{~mL} / \mathrm{min}$ at room temperature. The compounds were identified using waters 996 photodiode array detector of HPLC ${ }^{15}$ and finally with FTIR and NMR methods.IR spectrum of lecanoric acid was analysed with a FTIR spectrophotometer (Perkin Elmer, USA). Three $3 \mathrm{~mL}$ of mycobiont extract was placed directly on a sample holder 
of the infrared spectrometer and the data were collected over the wave number from $4000 \mathrm{~cm}^{-1}$ to $400 \mathrm{~cm}^{-1}$.

Structure elucidation of lecanoric acid by NMR technique and Identification of bioactive compounds using GC-MS.

The lecanoric acid structure was elucidated according to the procedure given by Sundholm and Huneck ${ }^{17}$. NMR analysis of lecanoric acid was carried out using the BRUKER-AMX400 $\mathrm{MHz}$ instrument. The TLC spot in the TLC plates was scraped and transferred to test tubes containing $1.5 \mathrm{~mL}$ of benzene-ethyl acetate (95:05). The suspension was centrifuged at $4000 \mathrm{rpm}$ for 20 minutes and the supernatant was collected and re-dissolved in DMSO for NMR analysis. The internal standard used was Tetramethyl silane and chemical shifts were articulated in ppm. GC-MS was done for the bioactive compounds in culture extract using the standard procedure ${ }^{18}$.

Antimicrobial assay of lecanoric acid

Antibiogram was done by disc diffusion method $^{19-21}$. In order to study the antimicrobial activity of culture extract, studies were carried out with different bacterial and fungal cultures such as Escherichia coli (MTCC 732), Staphylococcus aureus (MTCC 3160) and Vibrio cholera (MTCC 3901) and Aspergillus niger (MTCC 10180), Penicillium citrinum (MTCC 3234) and Candida albicans (MTCC 183); respectively. The cultures were procured from Microbial type culture collection (MTCC) at the institute of Microbial Technology (IMTECH), Chandigarh, India. These bacterial and fungal cultures were grown in MHB (Mueller Hinton Broth) and PDB (Potato Dextrose broth); respectively. A sterile cotton swab is soaked with the inoculum and remove the excess inoculum by pressing the swab against the inner surface of the flask. The swab was gently rubbing on the solid surface of PDA and Nutrient agar in different directions. About $50 \mu \mathrm{l}, 100 \mu \mathrm{l}$ and $150 \mu \mathrm{l}$ of mycobiont extract was loaded in a $6 \mathrm{~mm}$ sterile discs and tested against overnight grown cultures. After incubation at $37^{\circ} \mathrm{C}$ for $24 \mathrm{~h}$ for the bacteria and $25{ }^{\circ} \mathrm{C}$ for $48 \mathrm{hr}$ for the fungal strains, using a millimeter scale, the mean diameter of the inhibition zone was measured. Similarly, a known concentration of antibiotic standard $(30 \mu \mathrm{l})$ was prepared (Chloramphenicol for bacteria $(25 \mathrm{mg} /$ $\mathrm{mL}$ distilled water) and Fluconazole $(25 \mathrm{mg} / \mathrm{mL}$

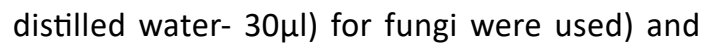
tested against the test strains. Each sample was tested in triplicates.

\section{Minimum Inhibitory concentration test}

The minimum microbicidal concentration test determines the assessment of the lowest concentration of certain lichen extracts or antibiotics that can inhibit 100 per cent of test microorganisms. The minimum inhibitory concentration (MIC) test was conducted as per the methods reported by Plaza et $a .^{22}$ using the 96-wells microtiter plate. The stock solution of the test sample was prepared by dissolving 80 $\mathrm{mg} / \mathrm{mL}$ of lichen compound and drug in $20 \%$ DMSO. Exactly $100 \mu \mathrm{L}$ of sterile Mueller-Hinton broth medium was added in each well. The test sample was tested by adding $100 \mu \mathrm{L}$ of the lichen compound from the stock solution in $100 \mu \mathrm{L}$ of sterile Mueller-Hinton broth medium in the first well. This was followed by transferring 100 $\mu \mathrm{L}$ of compound from first well to the second well containing $100 \mu \mathrm{L}$ of sterile $\mathrm{MH}$ broth. After transferring $100 \mu \mathrm{L}$, the final concentration of the lichen compound in the first well was $4 \mathrm{mg} / 100 \mu \mathrm{L}$. In this way, $100 \mu \mathrm{L}$ of extract was transferred up to seventh well. The dilution of the seventh well was $62.5 \mu \mathrm{g} / \mathrm{mL}$. Simultaneously, $100 \mu \mathrm{L}$ of the overnight culture (determined 0.5 MCFarland standard) (5 x $105 \mathrm{cfu} / \mathrm{mL}$ for bacteria and $5 \times$ $106 \mathrm{cfu} / \mathrm{mL}$ for fungi) was added in each well. The plate was incubated at $37^{\circ} \mathrm{C}$ for overnight The titre plates were examined for the complete absence of macroscopically visible turbidity.

\section{Resazurin test}

Alternatively, the lowest concentration of the lichen compound in which the turbidity completely absent was found out by adding the 30 $\mu \mathrm{L}$ resazurin $(0.05 \%$ in distilled water) indicator in to each well. The titre plate was incubated at $37^{\circ} \mathrm{C}$ for $4 \mathrm{hrs}$. The development of pink colour is the indication of excess microbial load. The resazurin test is based on development of pink the colour, greater was the total number of active microbial load in the well and lower was the activity of lichen compound. Positive control (100 $\mu \mathrm{L}$ of culture) and negative control (sterile broth alone) were also used.

Minimum Bactericidal concentration test (MBC) Minimum bactericidal activity was done by transferring $0.05 \mathrm{~mL}$ of the inoculum from 
the wells showing absence of turbidity to plates containing MHA agar and then observed for the plates in which bacterial cells were killed by the lichen compound and standard. The lowest concentration of the antibiotic in that well was noted. That concentration was the minimum bactericidal concentration of the lichen compound and standard.

\section{Minimum Fungicidal concentration test (MFC)}

Minimum bactericidal activity was done by transferring $100 \mu \mathrm{L}$ of the inoculum from the wells showing no turbidity to plates containing potato dextrose agar and then observed for the plates in which fungal cells were killed by the lichen compound. The lowest concentration of the lichen compound in that well was noted.
That concentration was the minimum fungicidal concentration of the lichen compound and the standard.

\section{Anti-proliferative activity of lecanoric acid}

Dalton's Lymphoma Ascites (DLA) cells were purchased from Amala Cancer Research Institute, Thrissur, Kerala, India. DLA cell lines were maintained in mice models by aseptic serial transplantation in Swiss albino mice from tumorbearing mice after $10^{\text {th }}$ day of ascites induction. DLA cells were freshly harvested from DLA-bearing mice and the cell count was adjusted to $1 \times 10^{5}$ cells/mL and plated onto 96 -well flat bottom culture plates with various concentrations of lecanoric acid. All cultures were incubated for $24 \mathrm{~h}$ at $37^{\circ} \mathrm{C}$ in a humidified incubator $\left(5 \% \mathrm{CO}_{2}\right.$

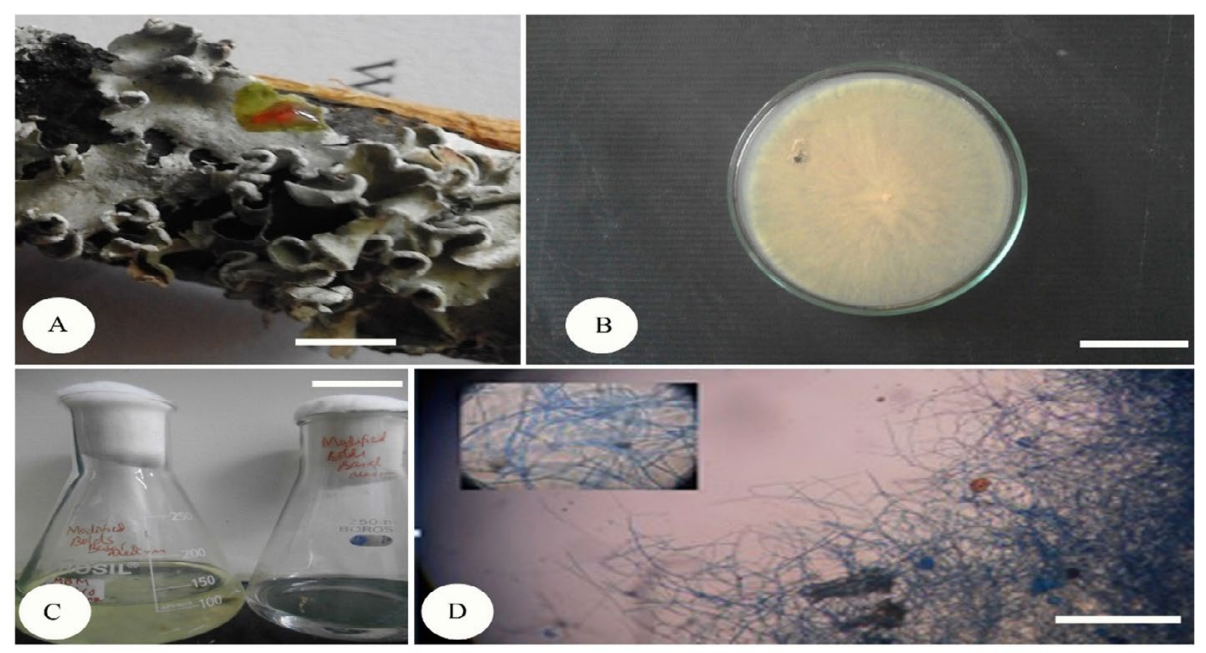

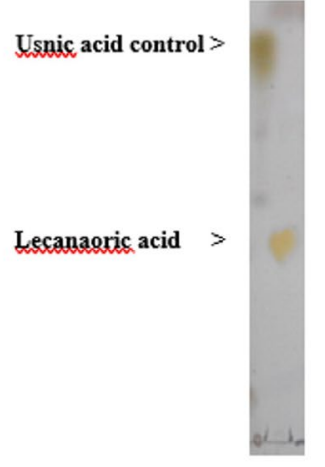

$\mathbf{E}$

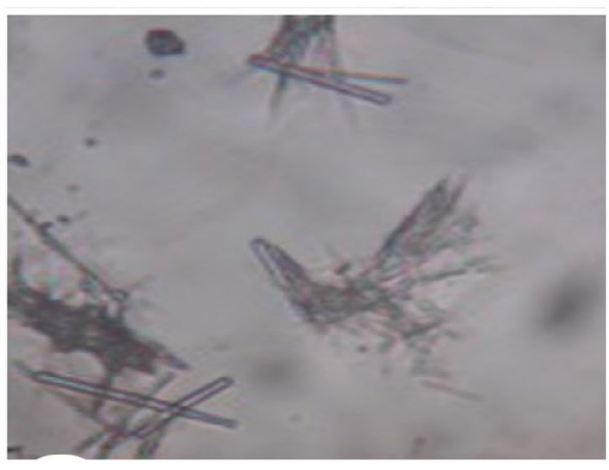

F

Fig. 1. In vitro mycobiont culture of $P$. austrosinense.

(A) P. austrosinense lichen thallus (Bar $3 \mathrm{~mm}$ ), (B) Cultured mycobiont on PDA media (Bar $1 \mathrm{~cm}$ ), (C) Growth of mycobiont in MBBS broth (Bar $2 \mathrm{~cm}$ ), (D) Microscopic view of mycobiont mycelium under 10X objective lens (Bar $25 \mu \mathrm{M}),(\mathrm{E}) \mathrm{TLC}$ of lecanoric acid, (F) Microcrystals of lecanoric acid (Bar $5 \mu \mathrm{M})$ 
in a humid atmosphere) with DMEM medium supplemented with FBS $10 \%$, penicillin $100 \mathrm{IU} /$ $\mathrm{mL}$, and streptomycin $100 \mathrm{mg} / \mathrm{mL}$. Proliferation of the cells was checked using MTT assay using different concentrations of lecanoric acid. About $10 \mu \mathrm{L}$ of MTT ( $5 \mathrm{mg} / \mathrm{mL}$ in PBS) was added to each well and the plate was incubated for $4 \mathrm{~h}$. The resulting formazan was dissolved in $100 \mu \mathrm{L}$ of dissolving buffer (10 g SDS in $100 \mathrm{~mL}$ water and $83 \mu \mathrm{L} 37 \% \mathrm{HCl}$ ) and absorbance of the solution was read at $595 \mathrm{~nm}$ using a scanning multi well Spectrophotometer (Biorad, Model 680, Japan) ${ }^{23}$ and the experiments were executed in triplicates.

\section{RESULTS}

The specimens were identified and confirmed by matching it with related specimens deposited at National Botanical Research Institute (NBRI), Lucknow, Uttar Pradesh, India for future reference (Accession No. 35618). The thallus of $P$. austrosinense in morphology appeared as greyish with foliose form and upper and lower surface corticated when looked under high power magnification (40X). This species produces the soredia, eciliate, unbranched rhizines which are the distinguishing characteristic feature of $P$. austrosinense. The identification of this species was further confirmed by spot tests (Fig. 1 A). In $\mathrm{K}$ test, the colour change of cortex from grey to yellow indicated positive for the test which is the characteristic reaction of atranorin. In C and KC tests, the colour change of medulla occurred from white to blood red it was due to lecanoric acid which indicated $\mathrm{C}+$ and $\mathrm{KC}+$ cortex. Thalli were $12 \mathrm{~cm}$ across and $16 \mathrm{~mm}$ wide, with sorediate and ecilaite lobes. Apothecia was not found. The mycobiont culture (Fig. 1B). from thallus of $P$. austrosinense showed with fuzzy mycelial growth on $6^{\text {th }}$ week of incubation (Fig. 1C). The most characteristic plectenchymatous tissue arrangement of mycobiont was observed under a microscope which showed a net like structure. The mycobionts cultured were lactophenol cotton blue stained (Fig. 1D). The filament was branched septate, firmLy glued together and formed anastomoses hyphae. The size of a hyphae cell was $15 \times 7.5 \mu \mathrm{M}$. Modified Bold's basal salt (MBBS with $1 \%$ sucrose) broth medium yielded 2.3 gm biomass (dry weight) and $1.27 \mu \mathrm{g}$ per gram atranorin and $1.98 \mu \mathrm{g}$ gram of lecanoric acid per $\mathrm{g}$ dry weight of mycobiont culture in $50 \mathrm{~mL}$ broth. As the sucrose level was insufficient (1\%) in the earlier stages the yield was comparatively low $(<0.01 \%)$. The yield was further improved by continuously introducing a fresh quantity of medium with high sucrose upto $4 \%$ which ensured a comparatively high yield of lichen compound (>0.01\%). The culture inoculated in MYE (Malt yeast extract) broth did not contain any lichen substances. A high sucrose

Table 1. UV Visible spectrum of lecanoric acid produced by the mycobiont of $P$. austrosinense

\begin{tabular}{lccc}
\hline $\begin{array}{l}\text { Peak } \\
\text { No. }\end{array}$ & $\begin{array}{c}\text { Peak } \\
\text { (AU) }\end{array}$ & $\begin{array}{c}\text { Peak } \\
(\mathrm{nm})\end{array}$ & $\begin{array}{c}\text { Peak } \\
(\mathrm{nm})^{*}\end{array}$ \\
\hline 1 & 3.902 & 214.61 & 213 \\
2 & 0.672 & 271.50 & 270 \\
3 & 0.496 & 306.25 & 304 \\
\hline
\end{tabular}

* As per the result of Yoshimura method (1994)

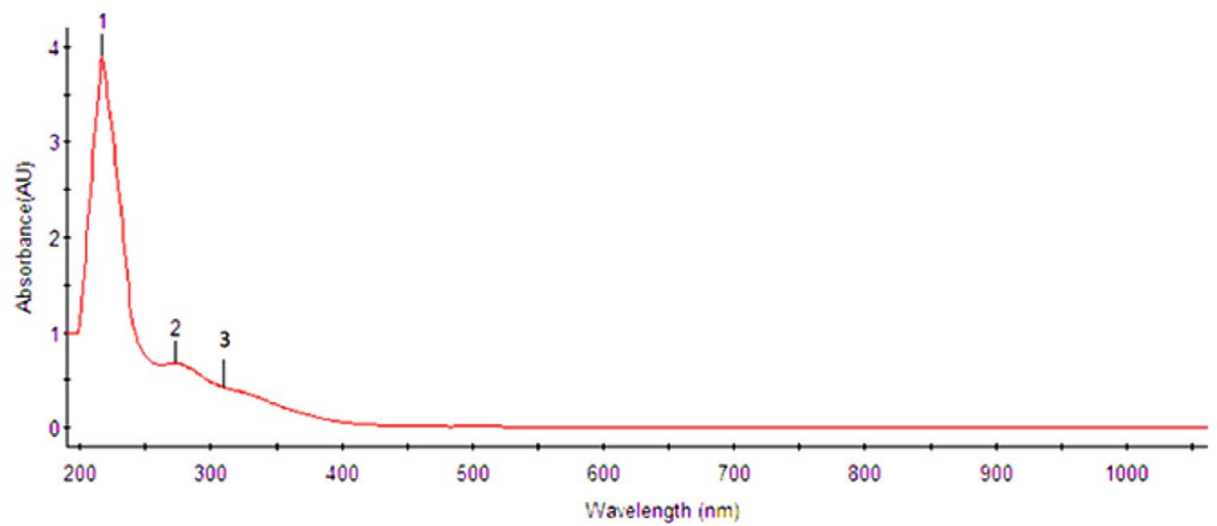

Fig. 2. UV-VIS Spectrophotometric analysis of lecanoric acid 
concentration (4\%) might have caused stress resulting in production of lichen compounds in Modified Bold's Basal Salt medium. The lecanoric acid was further eluted in column chromatography, purified and used for all further analysis.

\section{Confirmation of lecanoric acid}

On a developed TLC plate the lecanoric acid was the middle point at Rf class of 3 and $\mathrm{Rf}$ value of 0.27 while the control (usnic acid) was observed at Rf class 6 and Rf value at 0.7 . The colour of the lecanoric acid was observed as a yellowish spot encircled by grey circle while usnic acid was green in solvent system A (Fig. 1E). Crystals of the lichen compounds were known to exhibit different shapes and sizes. Thus, attempts were made to identify the size and shape of the crystals from the extract of culture filtrate through micro-crystallization method. The lecanoric acid formed was long straight crystals with 50 micron in length. The unbranched needles in clusters with star shaped structure under 40X were observed (Fig. 1F).

Identification of lecanoric acid was confirmed by peaks obtained from UV-VIS spectrophotometer as supplementary evidence. The maximum absorption wavelengths $\left(\lambda_{\max }\right)$ of lecanoric acid were found to be 214.61, 217.50 and $306.25 \mathrm{~nm}$ (Table 1 and Fig. 2). The HPLC profile of $P$. austrosinense culture extract was compared with the results given by Luo et al. ${ }^{23}$. It was identified that the lecanoric acid might be present in the extract. Similarly, based on the one single peak obtained with the retention time of $2.779 \mathrm{~min}$ it was shown that lecanoric acid might be present in the culture extract (Table 2 and Fig. 3). The prevailing stretching vibrations for various functional groups in the lecanoric acid of the P.austrosinense culture extract were aromatic, carboxylic, alkene and phenolic groups. This was identified from FTIR analysis (Table 3 and

Table 2. HPLC profile of lecanoric acid produced by the mycobiont of $P$. austrosinense

\begin{tabular}{lcccccl}
\hline Peak\# & Ret. Time & Area & Height & Area \% & Height \% & Compound confirmation \\
\hline 1 & 2.779 & 5411436 & 112430 & 100.000 & 100.000 & Lecanoric acid (Rt 2.781) \\
Total & - & 5411436 & 112430 & 100.000 & 100.000 & \\
\hline
\end{tabular}

Table 3. FTIR spectrum of lecanoric acid produced by the mycobiont of $P$. austrosinense

\begin{tabular}{lccc}
\hline S.No & Peak & Bond & Functional group \\
\hline 1. & 3446.50 & O-H stretch, H-bonded & Alcohols, phenols \\
2. & 1420.26 & C-C stretch (in-ring) & Aromatics \\
& 1022.43 & & \\
3. & 1118.50, & C-O stretch & Carboxylic acids \\
4. & 651.73 & = - H bend & Alkenes \\
\hline
\end{tabular}

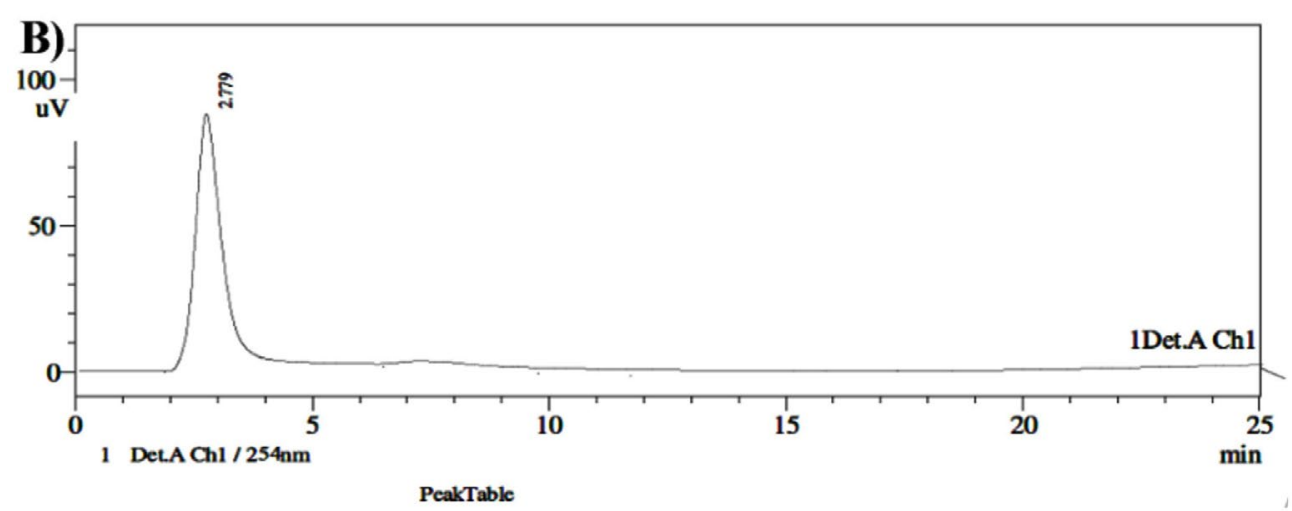

Fig. 3. HPLC analysis of lecanoric acid 
Fig. 4). Twenty bioactive lichen compounds were identified in the culture extract of $P$. austrosinense by GC MS analysis. The active principles with their Rt, molecular formula, and molecular weight are presented in Table 4 and and Fig. 5.

Identification of compound using NMR spectrum Based on the NMR spectral data, the compound isolated was identified as lecanoric acid. Its molecular formula is $\mathrm{C}_{16} \mathrm{H}_{14} \mathrm{O}_{7}$. The molecular weight was calculated as $318.28 \mathrm{~g} /$ mol. Supporting evidence for the structure of the lecanoric acid was provided by the analysis of ${ }^{1} \mathrm{H}$ NMR and ${ }^{13} \mathrm{C}-\mathrm{NMR}$ spectral (400 MHz, DMSO-d6) data showed sixteen carbon signals including two methyl and two carboxylic acid carbons. It was due to the methylation process at C-8 and 8'-position, signalling molecules were absorbed at $\delta 21.0$ and 21.3 ppm; respectively for methyl and carboxylic acid carbons. The results are shown in the Tables 5 and 6 and Fig. 6.

\section{Determination of antimicrobial activity}

The bactericidal and fungicidal activities of lecanoric acid purified from the mycobiont culture extract of lichen $P$. austrosinense were studied. The results showed that mycobiont extract registered a moderate antimicrobial activity against the test organisms (Table 7 and Fig. 7). The inhibition zone of lecanoric acid against $E$. coli was found to be highest $(8.60 \pm 0.60 \mathrm{~mm})$ and it was least with $V$. cholera $(7.80 \pm 0.54 \mathrm{~mm})$ among Gram's negative bacteria at $150 \mu \mathrm{L}$ of extract. Moreover, the zone of inhibition against

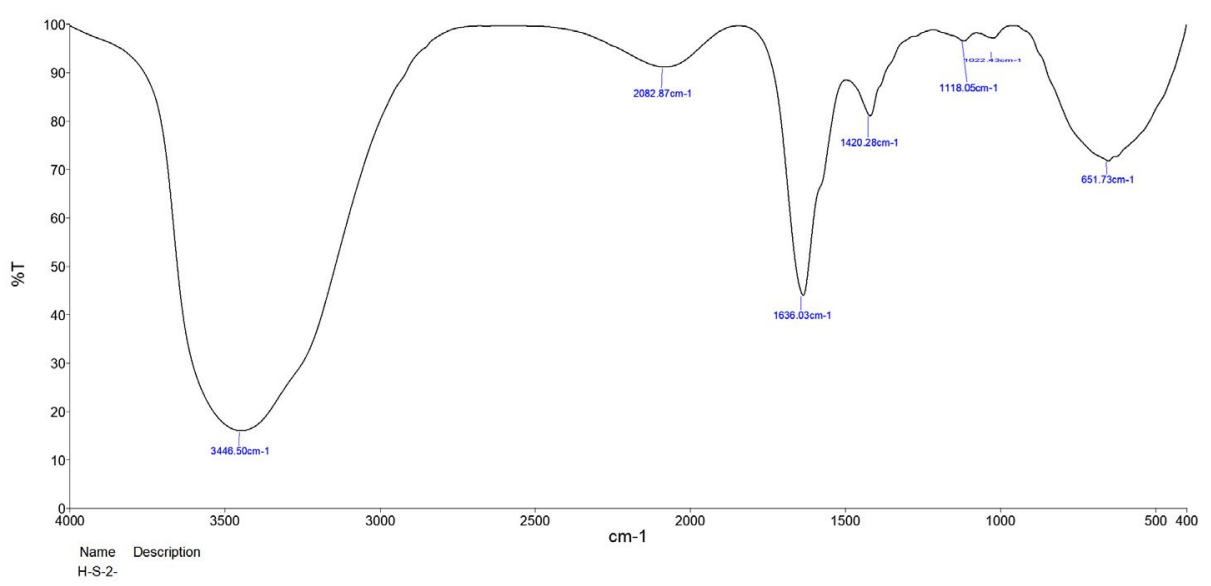

Fig. 4. FTIR spectrum analysis of lecanoric acid

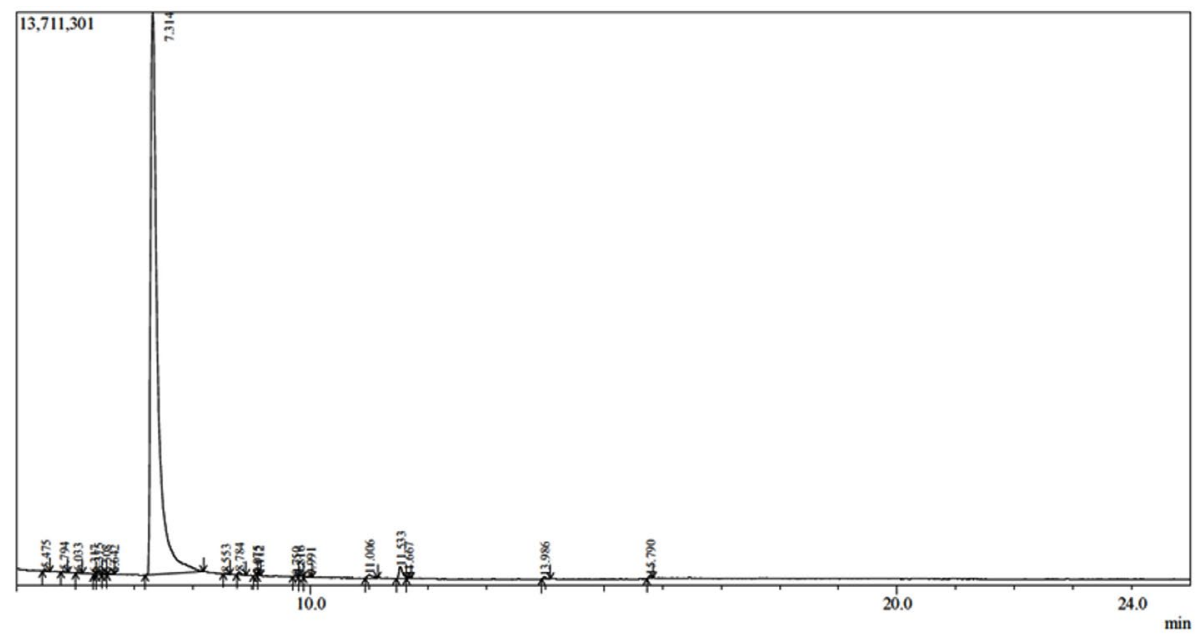

Fig. 5. GC-MS analysis of culture extract of $P$. austrosinense 
S. aureus was moderate $(8.05 \pm 0.56 \mathrm{~mm})$. The extract prevented the growth of $A$. niger with the maximum inhibition zone of $7.50 \pm 0.52$ and against Candida albicans and the value was $7.25 \pm 0.50 \mathrm{~mm}$. The mean diameter of the inhibition zone was low with the value of $7.05 \pm 0.49 \mathrm{~mm}$ against $P$. citrinum.

\section{Minimum Inhibitory Concentration}

The minimum inhibitory concentration of the lecanoric acid of the mycobiont culture extract against test strains showed ranges between $0.83 \pm 0.28 \mathrm{mg} / \mathrm{mL}$ and $2.3 \pm 1.5 \mathrm{mg} /$ $\mathrm{mL}$. Table 8 and Fig.8. It was observed that the lecanoric acid showed the maximum antimicrobial activity against $E$. coli $(0.83 \pm 0.28 \mathrm{mg} / \mathrm{mL})$. This compound also showed antimicrobial activity against yeast Candida albicans $(1.5 \pm 0.87 \mathrm{mg} /$ $\mathrm{mL}$ ) and the studies have shown a strong positive correlation between disc diffusion and MIC tests. The lowest MIC value was recorded against Penicillium citrinum with the value of $2.3 \pm 1.5 \mathrm{mg} /$ $\mathrm{mL}$. On comparison, it was seen that the antibiotic standard had the maximum antimicrobial activity against all test strains.

\section{Minimum Bactericidal Concentration}

The Minimum bactericidal concentration of the lichen compound lecanoric acid varied between $1.00 \pm 0.58 \mathrm{mg} / \mathrm{mL}$ and $1.3 \pm 0.58 \mathrm{mg} / \mathrm{mL}$ against E.coli and Vibrio cholerae respectively. The $\mathrm{MBC}$ of the standard drug chloramphenicol ranges between $0.05 \pm 0.03 \mathrm{mg} / \mathrm{mL}$ and $0.07 \pm 0.05 \mathrm{mg} /$ $\mathrm{mL}$ against E.coli and $V$. cholerae respectively. The results are shown in Table 9.

\section{Minimum Fungicidal Concentration}

The result of the MFC showed that the lowest concentration against the Candida albicans was $1.7 \pm 0.58$ while $2.3 \pm 1.5 \mathrm{mg} / \mathrm{mL}$ against the A.niger and P.citrinum. The minimum fungicidal concentration was observed against yeast compared with mold. The MFC of the fluconazole standard was varied between $0.12 \pm 0.00$ and $0.17 \pm 0.13 \mathrm{mg} / \mathrm{mL}$. The results are shown in Table 9.

\section{Anti-proliferative effects of lecanoric acid}

Anti-proliferative activity of lecanoric acid was studied using the DLA cell line model by means of cytotoxicity assay of cancer cells grown

Table 4. Identification of bioactive compounds in sample by GC MS analysis

\begin{tabular}{|c|c|c|c|c|c|}
\hline Peak\# & R. Time & $\begin{array}{l}\text { Area } \\
\%\end{array}$ & Name & $\begin{array}{l}\text { Molecular } \\
\text { formula }\end{array}$ & $\begin{array}{l}\text { Molecular } \\
\text { weight }\end{array}$ \\
\hline 1 & 5.475 & 0.14 & 2-Pentanone, 5-(1,2-propadienyloxy) & $\mathrm{C}_{8} \mathrm{H}_{2} \mathrm{O}_{2}$ & 140 \\
\hline 2 & 5.794 & 0.07 & Undecane, 2,4-dimethylylu & $\mathrm{C}_{13}^{8} \mathrm{H}_{28}^{2}$ & 184 \\
\hline 3 & 6.033 & 0.10 & Hexane, 2,4-dimethyl & $\mathrm{C}_{8} \mathrm{H}_{18}^{20}$ & 114 \\
\hline 4 & 6.317 & 0.10 & 1-Propyne (CAS) Propyne & $\mathrm{C}_{3} \mathrm{H}_{4}$ & 40 \\
\hline 5 & 6.375 & 0.20 & Nonane, 5-(1-methylpropyl) & $\mathrm{C}_{13}^{3} \mathrm{H}_{28}$ & 184 \\
\hline 6 & 6.508 & 0.12 & 4-Octanone (CAS) Butyl propyl ketone & $\mathrm{C}_{8} \mathrm{H}_{16}^{20} \mathrm{O}$ & 128 \\
\hline 7 & 6.642 & 0.08 & 3-Hexanone, 2,2-dimethyl & $\mathrm{C}_{8} \mathrm{H}_{16} \mathrm{O}$ & 128 \\
\hline 8 & 7.314 & 96.65 & 5-Methyl-1,3-benzenediol & $\mathrm{C}_{7} \mathrm{H}_{8} \mathrm{O}_{2}$ & 124 \\
\hline 9 & 8.553 & 0.05 & 1-Octanol, 2,2-dimethyl & $\mathrm{C}_{10} \mathrm{H}_{22} \mathrm{O}$ & 158 \\
\hline 10 & 8.784 & 0.20 & Piperitenone oxide & $\mathrm{C}_{10} \mathrm{H}_{14} \mathrm{O}_{2}$ & 166 \\
\hline 11 & 9.075 & 0.04 & 2-Cyano-succinonitrile & $\mathrm{C}_{5} \mathrm{H}_{3} \mathrm{~N}_{3}$ & 105 \\
\hline 12 & 9.112 & 0.05 & Decane, 3,7-dimethyl- & $\mathrm{C}_{12} \mathrm{H}_{26}$ & 170 \\
\hline 13 & 9.750 & 0.09 & 2-(Chloromethyl)-4-Nitroph enol & $\mathrm{C}_{7} \mathrm{H}_{6} \mathrm{C}_{1} \mathrm{NO}_{3}$ & 187 \\
\hline 14 & 9.816 & 0.11 & Butane, 2,2-Dimethyl & $\mathrm{C}_{6} \mathrm{H}_{14}$ & 86 \\
\hline 15 & 9.991 & 0.10 & 1,2-Benzoldicarbonsaeure & $\mathrm{C}_{20} \mathrm{H}_{26} \mathrm{O}_{4}$ & 330 \\
\hline 16 & 11.006 & 0.42 & 3-Oxatricyclo[3.3.2.0 2,4 ] DEC-7- & $\mathrm{C}_{9} \mathrm{H}_{10} \mathrm{O}_{2}$ & 150 \\
\hline 17 & 11.533 & 1.09 & $\begin{array}{l}\text { Mixture of .delta.(1(11))-Bicyclo } \\
{[5.4 .0] \text { unde }}\end{array}$ & $\mathrm{C}_{11} \mathrm{H}_{16} \mathrm{O}$ & 164 \\
\hline 18 & 11.667 & 0.07 & Heptane, 3,3,5-trimethyl & $\mathrm{C}_{10} \mathrm{H}_{22}$ & 142 \\
\hline 19 & 13.986 & 0.15 & Hexadecanoic & $\mathrm{C}_{16} \mathrm{H}_{32} \mathrm{O}_{2}$ & 256 \\
\hline 20 & 5.790 & 0.17 & 9-Octadecenoic acid, methyl ester & $\mathrm{C}_{19} \mathrm{H}_{36} \mathrm{O}_{2}$ & 296 \\
\hline
\end{tabular}


in 96-well culture plates containing high glucose Dulbecco's modified Eagle's medium amended with various nutrient sources. The results of both trypan blue exclusion test and MTT assay have proven the anti-proliferative effect of lecanoric acid against DLA cell line (Fig. 9). In lecanoric acid treated cells, cell shrinkage and morphological changes were observed, which suggested it to be

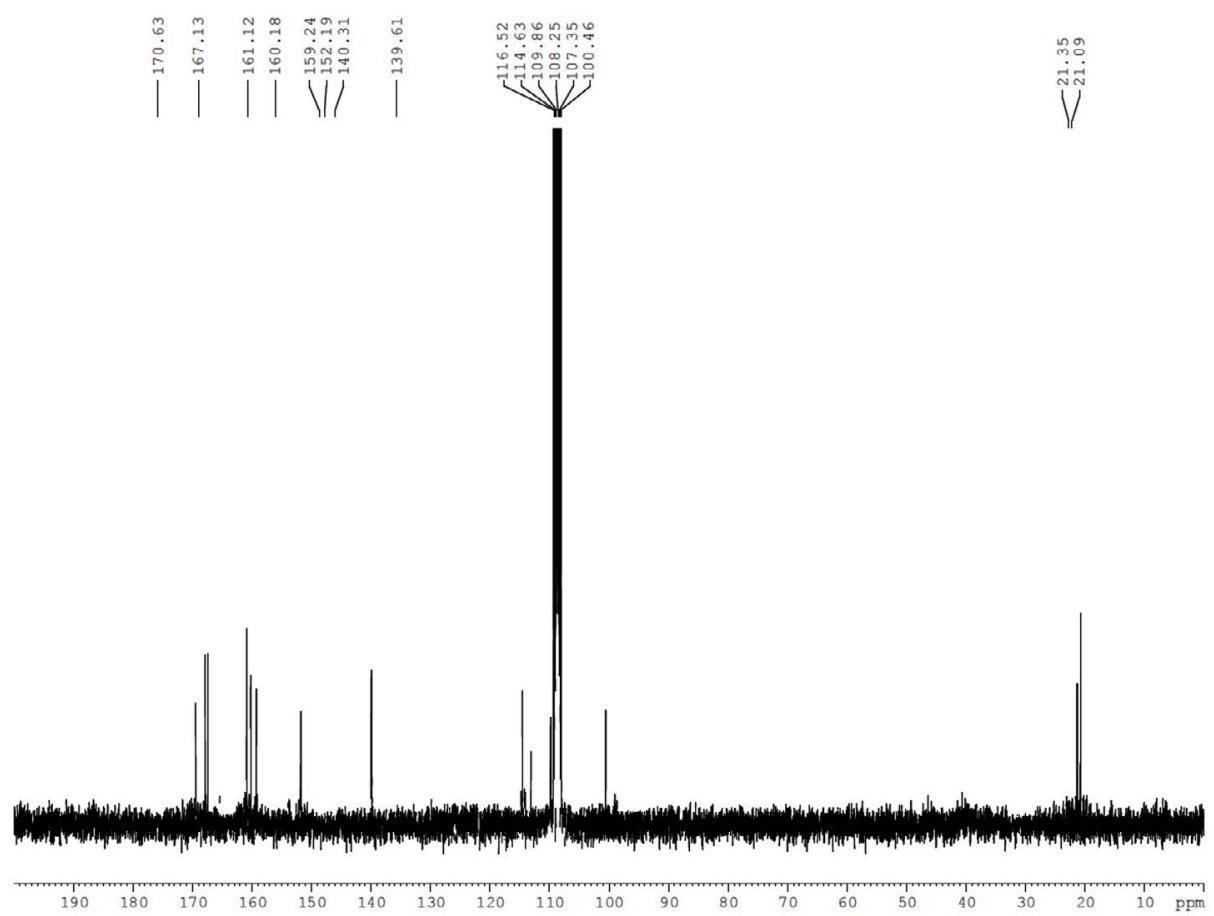

Fig. 6. ${ }^{13} \mathrm{C}-\mathrm{NMR}$ spectrum of lecanoric acid

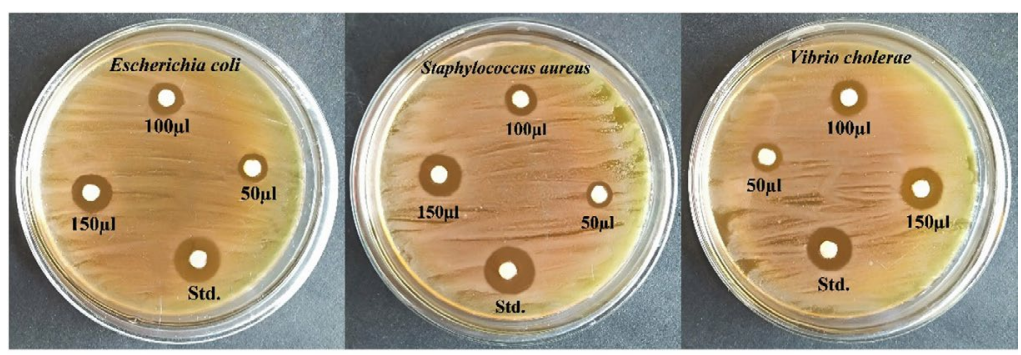

Escherichia coli Staphylococcus aureus Vibrio cholera

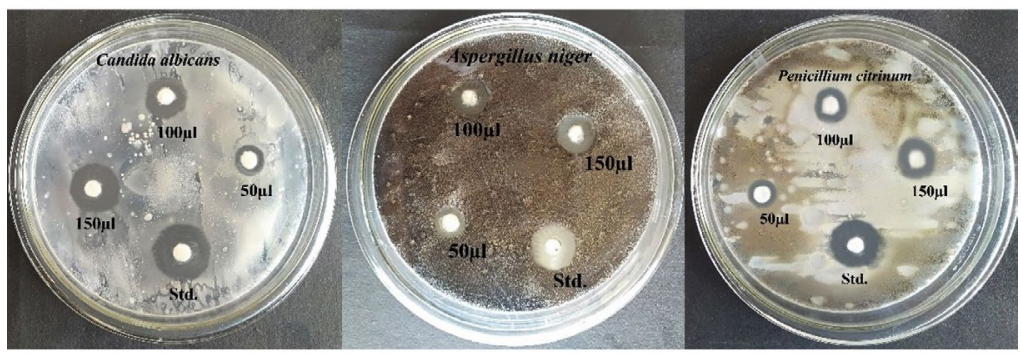

Candida albicans

Aspergillus niger Penicillium citrinum

Fig. 7. Antimicrobial activity of lecanoric acid against pathogenic bacterial and fungal strains 
Table 5. ${ }^{1} \mathrm{H}-\mathrm{NMR}$ spectral data of lecanoric acid

\begin{tabular}{lll}
\hline $\begin{array}{l}\text { Location of } \\
\text { Proton }\end{array}$ & Extract & Literature $^{34}$ \\
\hline 2 & 10.49 & $10.48(\mathrm{OH})$ \\
3 & 6.23 & $6.22(\mathrm{H})$ \\
4 & 10.48 & $10.47(\mathrm{OH})$ \\
5 & 6.63 & $6.62(\mathrm{H})$ \\
8 & 2.34 & $2.35(\mathrm{CH} 3)$ \\
$2^{\prime}$ & 10.32 & $10.33(\mathrm{OH})$ \\
$3^{\prime}$ & 6.59 & $6.60(\mathrm{H})$ \\
$5^{\prime}$ & 6.61 & $6.61(\mathrm{H})$ \\
$7^{\prime}$ & 10.01 & $10.01(\mathrm{COOH})$ \\
$8^{\prime}$ & 2.37 & $2.37(\mathrm{CH} 3)$ \\
\hline
\end{tabular}

an effective anticancer agent (Fig. 9A and B). The results further indicated that $\mathrm{IC}_{50}$ of lecanoric acid and the cell viability are negatively correlated. Cytotoxicity assay revealed that lecanoric acid exhibited cytotoxicity in a dose dependent manner. The growth inhibition was observed in lecanoric acid treated cell lines at 48 hours of incubation and cytotoxicity effect was compared with standard drug 5-fluorouracil. The inhibitory concentration
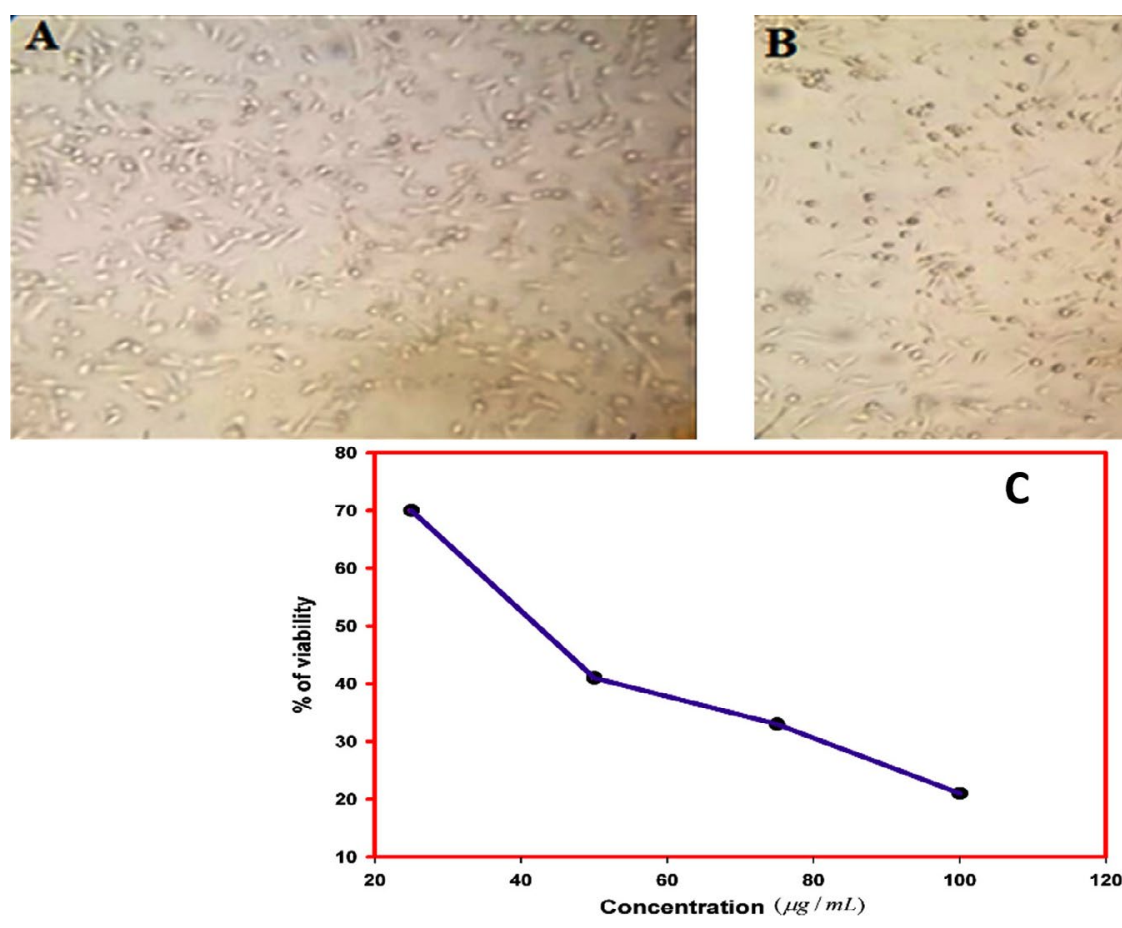

Fig. 9. Antiproliferative effect of lecanoric acid in DLA cell line (A) Morphological changes of DLA cells, (B) Shrinkage of DLA cells and (C) Effect of various concentration of lecanoric acid on viability of DLA cell by MTT assay

Journal of Pure and Applied Microbiology

Fig. 8. Antimicrobial activity of lecanoric acid against pathogenic microbial test strains using Minimum Inhibitory Concentration test

$\left(\mathrm{IC}_{50}\right)$ of lecanoric acid was found to be $42 \pm 1.5 \mu \mathrm{g} /$ $\mathrm{mL}$ (Fig. 9C).

\section{DISCUSSION}

Medicinal lichens have been traditionally used in the treatment of various diseases. Asian traditional medicinal systems such as Ayurvedha from India, Chinese - medicine (TCM), JapaneseChinese medicine are known systems to cure

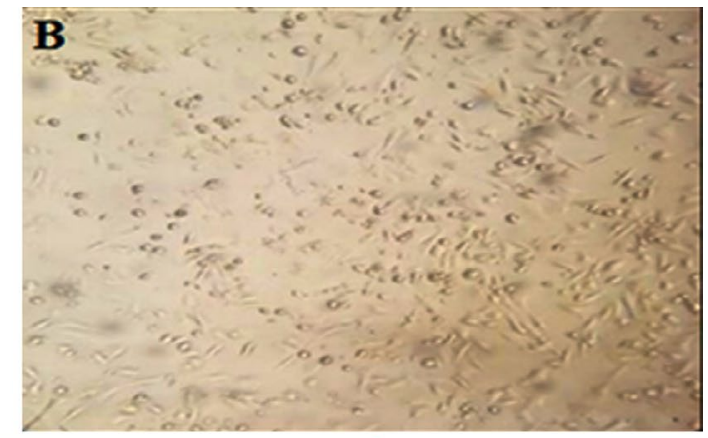


various diseases. In India, various plant extracts are used to cure cancer and microbial diseases. Recently, different plant extracts are screened for their anti cytotoxic, antimicrobial, antiinflammatory and anticytotoxic activities. Many

Table 6. ${ }^{13} \mathrm{C}-\mathrm{NMR}$ spectral data of lecanoric acid

\begin{tabular}{lll}
\hline $\begin{array}{l}\text { Location of } \\
\text { Carbon }\end{array}$ & Extract & Literature ${ }^{34}$ \\
\hline 1 & 108.25 & 108.2 \\
2 & 160.18 & 160.2 \\
3 & 100.46 & 100.5 \\
4 & 161.12 & 161.1 \\
5 & 109.86 & 109.9 \\
6 & 140.3 & 140.4 \\
7 & 167.1 & 167.1 \\
8 & 21.3 & 21.3 \\
$1^{\prime}$ & 116.5 & 116.4 \\
$2^{\prime}$ & 159.2 & 158.7 \\
$3^{\prime}$ & 107.3 & 107.4 \\
$4^{\prime}$ & 152.1 & 152.3 \\
$5^{\prime}$ & 114.6 & 114.8 \\
$6^{\prime}$ & 139.6 & 139.6 \\
$7^{\prime}$ & 170.7 & 170.7 \\
$8^{\prime}$ & 21.0 & 21.0 \\
\hline
\end{tabular}

lichen species and secondary lichen compounds from mycobiont are still unexplored, the reason being the lack of knowledge about the culture and extraction techniques and access to the lichens.

The present study was aimed to study the antimicrobial and anticytotoxic activity of mycobiont culture extract of Parmotrema austrosinense, the lichen found at the higher altitudes of Western Ghats. In mycobiont culture, Modified Bold's Basal broth is commonly used as the media for compound induction and extraction but it is now proved that this media containing high sucrose helps in the induction of bioactive compounds from the mycobiont culture. So, in the present study two media viz., MYE (Malt Yeast Extract) and Modified Bold's Basal broth media were used for the culturing and induction of lichen compounds. The bioactive compound detection in culture extract was taken as a strong pre-screening protocol for identification of lichen mycobiont culture. The Modified Bold's Basal broth medium was found to be ideal and thus suggest that this medium might possess basal essential elements for mycelial compound induction. The bioactive compound was extracted using the standard

Table 7. Anti-microbial activity of lecanoric acid produced by the mycobiont of $P$. austrosinense

\begin{tabular}{lcccc}
\hline \multirow{2}{*}{ Strains } & \multicolumn{3}{c}{ Lecanroic acid Concentration $(\mu \mathrm{L})$} & \multirow{2}{*}{ Std. $(30 \mu \mathrm{L})$} \\
\cline { 2 - 4 } & 50 & 100 & 150 & \\
\hline Escherichia coli & $3.35 \pm 0.23$ & $5.20 \pm 0.36$ & $8.60 \pm 0.60$ & $11.75 \pm 0.82$ \\
Staphylococcus aureus & $2.60 \pm 0.18$ & $4.90 \pm 0.34$ & $8.05 \pm 0.56$ & $11.50 \pm 0.80$ \\
Vibrio cholera & $2.15 \pm 0.15$ & $4.35 \pm 0.30$ & $7.80 \pm 0.54$ & $11.30 \pm 0.79$ \\
Candida albicans & $2.05 \pm 0.14$ & $4.40 \pm 0.30$ & $7.50 \pm 0.52$ & $10.80 \pm 0.75$ \\
Aspergillus niger & $1.95 \pm 0.13$ & $4.15 \pm 0.29$ & $7.25 \pm 0.50$ & $10.60 \pm 0.74$ \\
Penicillium citrinum & $1.80 \pm 0.12$ & $4.00 \pm 0.28$ & $7.05 \pm 0.49$ & $10.35 \pm 0.72$ \\
\hline
\end{tabular}

Values expressed as Mean \pm SD in $\mathrm{mm}$; Standard: Chloramphenicol and Fluconazole

Table 8. Minimum Inhibitory Concentration data of lecanoric acid and standard

\begin{tabular}{llcc}
\hline SI. No & Test Strains & $\begin{array}{c}\text { MIC of lecanoric } \\
\text { acid }(\mathrm{mg} / \mathrm{mL})\end{array}$ & $\begin{array}{c}\text { MIC of antibiotic } \\
\text { standard }(\mathrm{mg} / \mathrm{mL})\end{array}$ \\
\hline 1 & Escherichia coli & $0.83 \pm 0.28$ & $0.04 \pm 0.03$ \\
2 & Staphylocccus aureus & $1.17 \pm 0.77$ & $0.06 \pm 0.05$ \\
3 & Vibrio cholerae & $1.33 \pm 0.58$ & $0.07 \pm 0.05$ \\
4 & Candida albicans & $1.5 \pm 0.87$ & $0.12 \pm 0.00$ \\
5 & Aspergillus niger & $2.17 \pm 1.75$ & $0.13 \pm 0.11$ \\
6 & Penicillium citinum & $2.33 \pm 1.53$ & $0.17 \pm 0.14$ \\
\hline
\end{tabular}

Values expressed as Mean \pm SD; Standard: Chloramphenicol and Fluconazole 
Table 9. MBC and MFC data of lecanoric acid and standard

\begin{tabular}{llll}
\hline SI. No & Test Strains & $\begin{array}{c}\text { MBC and MFC of } \\
\text { lecanoric acid } \\
(\mathrm{mg} / \mathrm{mL})\end{array}$ & $\begin{array}{c}\text { MFC of antibiotic } \\
\text { standard } \\
(\mathrm{mg} / \mathrm{mL})\end{array}$ \\
\hline 1 & Escherischia coli & $1.0 \pm 0.00$ & $0.05 \pm 0.03$ \\
2 & Staphylocccus aureus & $1.3 \pm 0.58$ & $0.07 \pm 0.05$ \\
3 & Vibrio cholerae & $1.3 \pm 0.58$ & $0.07 \pm 0.04$ \\
4 & Candida albicans & $1.7 \pm 0.58$ & $0.13 \pm 0.00$ \\
5 & Aspergillus niger & $2.3 \pm 1.53$ & $0.14 \pm 0.09$ \\
6 & Penicillium citinum & $2.3 \pm 1.53$ & $0.17 \pm 0.13$ \\
\hline
\end{tabular}

Values expressed as Mean \pm SD; Standard: Chloramphenicol and Fluconazole

protocol and the results are found to be consistent with the work done by Muggia et al. ${ }^{24}$

Although water is universal solvent for extraction, acetone helps in the faster extraction of lichen compounds from the lichens. So, in the present investigation, acetone was used for the extraction of lecanoric acid. The extract was evaporated in vacuo to get dry powder. The compounds were eluted in a silica gel column. The bioactive compound in the extracts were eluted using the standard protocol and the results were found to be consistent with the work done by Jayaprakasha et $a l .^{25}$

The standard antimicrobial test was done with the mycobiont culture extract. The acetone extracts of the culture showed moderate zone of inhibition. The antimicrobial activity of lecanoric acid in the culture extract was inhibitory to both the Gram positive and Gram negative test strains in the present study and the results were not found to be consistent with the work done by Felczykowska et al. ${ }^{26}$ Because, types of test strains also differ genetically from one another thus they may react differently to a given lichen compound. Several studies have shown a strong positive correlation with the present study that the lichen compounds are equally effective against both the Gram positive and Gram negative test strains. The reference antibiotic chloramphenicol and fluconazole showed strong antimicrobial activity against all tested microbial strains. It is observed that the Aspergillus niger and Penicillium citrinum showed least susceptibility towards antimicrobial agents. This may be due to the presence of poor permeable polysaccharides viz., glucan and chitin on their fungal cell wall.
The result also suggests that the drug sensitivity of the test strains and concentration of the drug might be playing important role in potency of any antimicrobial agent. The supportive antimicrobial results facilitated the isolation of lecanoric acid and subjected to further investigations to prove their MIC, MBC, MFC and antiproliferative activity.

The results obtained in minimum inhibitory concentration assay, on comparison with disc diffusion test, suggested the zone of inhibition is always inversely proportional to the minimum inhibitory concentration of the drug. The result of this MIC test too suggests that this lichen compound lecanoric acid might possess potent antimicrobial property. On comparison with the standard drug such as chloramphenicol and fluconazole, it was seen that the lecanoric acid of the lichen compound had the moderate antimicrobial activity. Previous work with these clinical drugs has demonstrated the MIC values were varied between 512 and 1 $\mu \mathrm{g} / \mathrm{mL}$ for chloramphenicol and 125 and $64 \mu \mathrm{g} /$ $\mathrm{mL}$ for flucanzaole ${ }^{22}$. The MIC value of fluconazole was found to be $0.12 \pm 0.00 \mathrm{mg} / \mathrm{mL}$ against Candida albicans while chloramphenicol was varied between $0.04 \pm 0.03$ and $0.07 \pm 0.05 \mathrm{mg} / \mathrm{mL}$ against E.coli and Vibrio cholerae in the present study. This is supportive in accordance with the previous literature ${ }^{27}$.

The standard minimum bactericidal concentration assay was done with the lichen compound of mycobiont culture extract. The lecanoric acid showed moderate bactericidal activity. Plaza et al. ${ }^{22}$ reported the MBC values of ethanolic extract of lichen species such as Everniastrum vexans and Peltigera laciniata against 
Proteus vulgaris varied between $7.4 \pm 0.5 \mathrm{mg} / \mathrm{mL}$ and $35.7 \pm 2.2 \mathrm{mg} / \mathrm{mL}$ respectively while ethanolic extract of P.reticulatum showed $17.9 \pm 2.2 \mathrm{mg} / \mathrm{mL}$ against S.aureus. Similarly, the acetone extract of mycobiont culture of P.austrosinense was found to have moderate $\mathrm{MBC}$ values were varied between $1.0 \pm 0.00 \mathrm{mg} / \mathrm{mL}$ and $1.3 \pm 0.58 \mathrm{mg} / \mathrm{mL}$ while $1.17 \pm 0.77 \mathrm{mg} / \mathrm{mL}$. The bactericidal concentration required for complete killing depend upon the purity of compound and the genetic variation in the susceptibility of the test strains. The variations in the $\mathrm{MBC}$ results may also be due to the type of solvent extracts, type of lichen species and the presence of bioactive compounds in the extract. The lecanoric acid of mycobiont culture extract showed moderate bactericidal activity when compared with antibiotic standard.

MFC

The MBC and MFC assay show the microbicidal activity of the lecanoric acid and this study is the pioneering attempt with this mycobiont culture extract to assay the bactericidal and fungicidal activities against the test strains. The studies have shown a positive correlation between fungicidal effect against yeast and mold. Previous literature ${ }^{28}$ has reported the presence of antifungal and fungicidal activity of lecanoric acid against Trichophyton longifusus, T.mentagrophytes with the MIC value were $200 \mu \mathrm{g} / \mathrm{mL}$ and $16.9 \mu \mathrm{g} / \mathrm{mL}$ which acted as supportive evidence for antifungal activity of lecanoric acid of the present study. On comparison with the fluconazole standard, it was observed that the lecanoric acid had the moderate fungicidal activity.

Based on the antimicrobial assays, it is concluded that the lecanoric acid possesses potent microbicidal activity comparable with antibiotic standard.

The anti-proliferative activity of lecanoric acid was studied using DLA cell line by means of cytotoxicity assay. Lecanoric acid showed dose dependent antiproliferative activity against cancer cell lines. It was observed that lecanoric acid treated cells were found to cause cell shrinkage, swelling and membrane blebbing. The result suggests that this compound might possess potent cytotoxic activity. A substantial decrease in the cell viability was observed with increase in the concentration of lecanoric acid. This may be due to the presence of phenolic compounds. This is supportive in accordance to the report given by Ristic et al. ${ }^{29}$

So, further assays were done with the acetone extracts of the mycobiont culture. Previous work with these P.austrosinense thallus extract has demonstrated the presence of polyphenolic depsides in the acetone extracts of the thallus extract. In the present study, HPLC, UVVis spectrophotometric profiling were done. This is the first analysis with this lichen P.austrosinense mycobiont culture extract. The peaks obtained on comparison with the standard data, suggested the presence of lichen compound lecanoric acid with antitumour and antimicrobial activity. Encouraged by these results, the next step was the structure elucidation by standard procedure after the bioactive compound purification. Previous work with the lecanoric acid has demonstrated the chemical shifts of compounds in $\mathrm{NMR}^{28-30}$. The NMR, microcrystal and TLC results confirmed the presence of lichen compound lecanoric acid. The supporting evidence of microcrystal is taken as a strong pre screening rapid, reliable test for the detection of lichen compound, lecanoric acid in the mycobiont culture extract. The shape of crystals under the microscope are used to distinguish the lichen compound present in the solvent extract and it was found to be long needles. The results suggested that the extract might possess lichen compound lecanoric acid. Previous work carried out by Anjali et al. ${ }^{30}$ with the closely related species has demonstrated the presence of depside lecanoric acid in the extract at RF class 3 . The TLC results of the $P$. austrosinense mycobiont culture extract is supportive in accordance to the results described by Jayaprakasha et al. ${ }^{31}$ from closely related species of $P$. tinctorum with the $\mathrm{Rf}$ value of lecanoric acid was at 0.27 in Benzene and ethyl acetate solvent. Previous work with the lichen compound in TLC demonstrated that the $\mathrm{Rf}$ value of lichen compound might change slightly in different solvent system (solvent system A, solvent system B or solvent system $C$ ), but it is concluded that the Rf classes which depended only on the relative order of spot and found to be more constant. So, the spot obtained on comparison with standard Rf class, suggested the presence of lichen compound lecanoric acid in the culture extract. The UV result was interpreted from the values of wavelengths $\left(\lambda_{\max }\right)^{17}$. The result findings 
of Yoshimura et al. ${ }^{15}$ with the $\lambda_{\max }$ values of 212 , 270 and $304 \mathrm{~nm}$ acted as supportive evidence for UV-Vis spectrophotometric absorbance peak of lecanoric acid of this present study. The HPLC result of the present study is in agreement to the results of Luo et al. ${ }^{32}$ with the Rt value of 2.781. Encouraged by the above results, the next procedure was the structure elucidation by NMR after the active compound purification. A lichen compound was identified as lecanoric acid.

\section{CONCLUSION}

Several lichen species are being tested for their cytotoxic and antimicrobial properties. Many factors are important to prove their biological activities. The mycobiont culture of $P$. austrosinense lichen species is least explored and was taken for the present investigation. The purified extract of mycobiont culture was subjected to antimicrobial and anti-proliferative assays using the standard procedure. The supportive results suggested the biological activity of lecanoric acid. Based on the above findings, it can be concluded that this compound can be subjected to further investigations to prove their anticancer activity.

\section{ACKNOWLEDGMENTS}

Our research was supported by ICMR. The authors are much indebted to thank Dr. A. Rajendran, Professor and Head, Department of Botany, Bharathiar University, Coimbatore, Tamil Nadu, India for his critical comments and constant encouragement. The authors are thankful to Dr. Sanjeeva Nayaka, Lichenology Laboratory, CSIRNational Botanical Research Institute, Lucknow, Uttar Pradesh, India for identification of lichen samples.

\section{CONFLICT OF INTEREST}

The authors declare that there is no conflict of interest.

\section{AUTHORS' CONTRIBUTION}

$P P$ - Designed the experiments and analysed the data, KR - Performed the experiments, Data collection and wrote the manuscript, SP Edited the manuscript. All Authors revised and approved the final article.

\section{FUNDING}

This study was supported by Indian Council of Medical Research, New Delhi [Ref. No.: 58/18/2015-TFV/ BMS/ dated 23-02-2018].

\section{DATA AVAILABILITY}

All datasets analyzed during this study are included in the manuscript

\section{ETHICS STATEMENT}

This article does not contain any studies with human participants or animals performed by any of the authors.

\section{REFERENCES}

1. BrayF, FerlayJ, Soerjomataram I, Siegel RL, Torre LA, Jemal A. Global cancer statistics 2018: GLOBOCAN estimates of incidence and mortality worldwide for 36 cancers in 185 countries. CA: A Can J Clin. 2018;68(6):394-424. doi: 10.3322/caac. 21492

2. Kalidoss R, Mariraj M, Shenbagam M. Anti-microbial and anti-oxidant properties of solvent extract of lichen species collected from Kodaikanal hills, Western Ghats of Tamil Nadu, India. In: Phytomedicine. CRC Press, London, UK; 2020:53-61. doi: 10.1201/9781003014898-8

3. Fazoli K, dos Santos I, Caetano Ic. Antibiotic resistance in Enterobacteriaceae family members isolated from horses used for animal traction. J Pure Appl Microbiol. 2020;14(2):1149-1156. doi: 10.22207/JPAM.14.2.10

4. Yamamoto $Y$, Miura $Y$, Kinoshita $Y$, Screening of tissue cultures and thalli of lichens and some of their active constituents for inhibition of tumor promoter-induced epstein-barr virus activation. Chem Pharm Bull. 1995;43(8):1388-1390. doi: 10.1248/cpb.43.1388

5. Hager A, Brunauer G, Worgotter ES. Investigations on secondary metabolites of lichens and lichen mycobionts in culture: Production and biological activity. Osterreichische. 2008:323-324.

6. Shrestha G, El-Naggar AM, Clair LLS, O'Neill $\mathrm{KL}$. Anticancer activities of selected species of North American lichen extracts. Phytother Res. 2015;29(1):100-107. doi: 10.1002/ptr.5233

7. Hamada N, Ueno T. Lecanoric acid from the mycobiont of the lichen Stereocaulon curtatum. Phytochem. 1990;29(2):678-679. doi: 10.1016/00319422(90)85147-8

8. Yoshimura I, Yamamoto Y, Nakano T, Finnie J. Isolation and culture of lichen Photobionts and Mycobionts. In: Kranner IC, Beckett RP, Varma AK, eds. Protocols in Lichenology: Culturing, Biochemistry, Ecophysiology and Use in Biomonitoring. Springer Lab Manuals. Berlin, Heidelberg: Springer. 2002:3-33. doi: 10.1007/978-3-642-56359-1_1

9. Upreti DK, Divakar PK, Nayaka $\bar{S}$. Commercial and ethnic use of lichens in India. Econ Bot. 2005;59(3):269-273. doi: 
10.1663/0013-0001(2005)059[0269:CAEUOL]2.0.CO;2

10. Hur J-S, Kim H-J, Lim K-M, Koh Y-J. Isolation, cultivation, and antifungal activity of a Lichen-forming fungus. Plant Pathol J. 2003;19(2):75-78. doi: 10.5423/ PPJ.2003.19.2.075

11. Walker FJ, James PW. A Revised Guide to Microchemical Techniques for the Identification of Lichen Products. British Lichen Society. 1980.

12. Awasthi DD. Compendium of the Macrolichens from India, Nepal and Sri Lanka. Bishen Singh Mahendra Pal Singh; India. 2007.

13. Verma N, Behera BC. In Vitro Culture of Lichen Partners: Need and Implications. In: Upreti DK, Divakar PK, Shukla V, Bajpai R, eds. Recent Advances in Lichenology: Modern Methods and Approaches in Lichen Systematics and Culture Techniques. Springer India, New Delhi. 2015;2:147-159. doi: 10.1007/97881-322-2235-4_8

14. Orange A, James PW, White FJ. Microchemical Methods for the Identification of Lichens. Twayne Publishers; New Delhi. 2001.

15. Yoshimura I, Kinoshita Y, Yamamoto Y, Huneck S, Yamada Y. Analysis of secondary metabolites from Lichen by high performance liquid chromatography with a photodiode array detector. Phytochem Anal. 1994;5(4):197-205. doi: 10.1002/pca.2800050405

16. Cordeiro LMC, lacomini M, Stocker-Worgotter E. Culture studies and secondary compounds of six Ramalina species. Mycolo Res. 2004;108(5):489-497. doi: 10.1017/S0953756204009402

17. Sundholm EG, Huneck S. C-13 NMR-spectra of lichen depsides, depsidones and depsones. 1. Compounds of the orcinol series. Chemica Scripta. 1980;16(5):197200.

18. Srinivasan K, Sivasubramanian S, Kumaravel S. Phytochemical profiling and GC-MS study of Adhatoda vasica leaves. Int J Pharm Bio Sci. 2013;5(1):714-720.

19. Kirby WM, Yoshihara GM, Sundsted KS, Warren JH. Clinical usefulness of a single disc method for antibiotic sensitivity testing. Antibiot Annu. 1956:892-897.

20. Bauer AW, Perry DM, Kirby WMM. Single-Disk Antibiotic-Sensitivity Testing of Staphylococci: An Analysis of Technique and Results. AMA Arch Intern Med. 1959;104(2):208-216. doi: 10.1001/ archinte.1959.00270080034004

21. Gao Y, Arokia Vijaya Anand M, Ramachandran V. Biofabrication of zinc oxide nanoparticles from Aspergillus niger, their antioxidant, antimicrobial and anticancer activity. J Clust Sci. 2019;30(4):937-946. doi: 10.1007/s10876-019-01551-6

22. Plaza CM, Salazar CPD, Plaza RE. In vitro analysis of antibacterial and antifungal potential of lichen species of Everniastrum of vexans, Parmotrema blanquetianum, Parmotrema reticulatum and Peltigera laciniata. MOJ Drug Des Develop Ther. 2018;2(3):125134. doi: $10.15406 /$ mojddt.2018.02.00038

23. Mariadoss AVA, Ramachandran V, Shalini V. Green synthesis, characterization and antibacterial activity of silver nanoparticles by Malus domestica and its cytotoxic effect on (MCF-7) cell line. Microbial Pathogenesis. 2019;135:103609. doi: 10.1016/j. micpath.2019.103609

24. Muggia L, Kopun T and Grube M,. Effects of Growth Media on the Diversity of culturable fungi from lichens. Molecules. 2017;22(824):1-22. doi: 10.3390/ molecules 22050824

25. Jayaprakasha G, Rao L, Singh R, Sakariah K. Improved chromatographic method for the purification of phenolic constituents of the lichen Parmotrema tinctorum (Nyl.) Hale. J Chromatog Sci. 1998;36(1): 8-10. doi: 10.1093/chromsci/36.1.8

26. Felczykowska AA, Pastuszak - Skrzypczak, Pawlik A, Bogucka K, Herman - Antosiewicz A, Guzow Krzeminska B. Antibacterial and anticancer activities of acetone extracts from in vitro cultured lichen-forming fungi. BMC Comp Alter Med. 2017;17(300):4-12. doi: 10.1186/s12906-017-1819-8

27 Narwal S, Kumar S, Verma PK. Synthesis and therapeutic potential of quinoline derivatives. Res Chem Interm. 2017;43(5):2765-2798. doi: 10.1007/ s11164-016-2794-2

28. Furmanek L, Czarnota P, Seaward, MRD. Antifungal activity of lichen compounds against dermatophytes: a review. J Appl Microbiol. 2019;127(2):308-325. doi: 10.1111/jam.14209

29. Ristic S, Rankovic B, Kosanic M. Phytochemical study and antioxidant, antimicrobial and anticancer activities of Melanelia subaurifera and Melanelia fuliginosa lichens. J Food Sci Technol. 2016;53(6):2804-2816. doi: 10.1007/s13197-016-2255-3

30. Anjali DB, Mohabe S, Reddy AM, Nayaka S. Antimicrobial activities of 2-Propanol crude extract from lichen Parmotrema tinctorum (Despr. ex. Nyl.) Hale, collected from Eastern Ghats, India. Curr Res Environ Appl Mycol. 2015;5(3):160-168. doi: 10.5943/cream/5/3/1

31. Jayaprakasha GK, Rao LJ. Phenolic constituents from lichen Parmotrema stuppeum (Nyl.). Hale and their antioxidant activity. Z. Naturforsch. 2000;55:10181022. doi: 10.1515/znc-2000-11-1227

32. Luo H, Yamamoto Y, Kim JA, Jung JS, Koh YJ, Hur J-S. Lecanoric acid, a secondary lichen substance with antioxidant properties from Umbilicaria antarctica in maritime Antarctica (King George Island). Polar Biol. 2009;32(7):1033-1040. doi: 10.1007/s00300-0090602-9 